The Dorothy House Hospice Care RUH Compassionate Companions service is a joint partnership between Dorothy House Hospice Care and the Royal United Hospitals Bath NHS Foundation Trust (RUH) Palliative Care and End of Life Team. This inspiring and progressive approach to caring for people was launched on 15 May 2019 with the support from the RUH Forever Friends Appeal and funding from the Sperring Trust for three years.

- To support the provision of compassionate and dignified care at the end of life for those dying in hospital, whilst aiming to improve carer outcomes reported through the bereavement feedback questionnaire;

- The service will supplement the quality nursing care that patients require in their final days or hours of life. Being able to spend time sitting with a dying patient, talking to them and their family and listening can be an enormous comfort at an emotionally challenging time for patient, family and ward staff;

- To provide a 7 day service that meets the needs of patients, carers and their families throughout the hospital. Volunteers work up to three-hour shifts from 9 am -9 pm;

- Provide extra care and support for patients who are thought to be in the last 48 hours of life, are inpatients at RUH, and have limited or no family support or have family that would benefit from respite;

- The service is starting with three wards and will expand to cover the whole hospital.

\section{P-230 COMPASSIONATE COMPANIONS: QUEENSCOURT VOLUNTEERS IN HOSPITAL}

Helen Birch, Julie Davidson, Louise Charnock. Queenscourt Hospice, Southport, UK

\subsection{6/bmjspcare-2019-HUKNC.252}

Background It was recognised there was a gap in companionship and empathic support for certain patients in hospital approaching end of life.

Aim Queenscourt in Hospital, an extension of Queenscourt Outside Volunteer Service, is launched to provide comfort and companionship for patients in hospital who are in the last hours to days of life, and whose families are absent or need support to take a short break.

Method Volunteers are recruited with previous health and social care experience and who are available at very short notice to respond to patient's changing condition. Volunteers are aligned with the hospice's vision and values. A bespoke training programme was put in place to prepare, educate and allay any potential anxieties and fears.

Results Patients eligible to benefit from service are identified by members of the Queenscourt Supportive and Specialist Palliative Care Services working in hospital. Volunteers may read quietly, provide gentle hand massage or may just simply be present. Volunteers may escalate a patient's needs and concerns to the ward staff if unsettled. Volunteers are fully debriefed following each shift and consequently report feeling empowered and valued for having made a difference. Challenges around hospital policies and procedures were overcome by liaising between HR departments, and open communication.

Conclusion Queenscourt delivers compassionate and emotional support to patients and their families across all settings. Our new volunteers in hospital are an integral part of this. By enlisting the support of volunteers, patients in hospital who are reaching the end of their lives have an empathic presence and companion by their side. We aim to support more people dying in hospital and communicate with secondary care colleagues ensuring all professional boundaries are respected. Training and support of volunteers ensures retention and continuation of a worthwhile service.

\section{P-231 USING VOLUNTEERS FOR BEDSIDE COMPANIONS TO SUPPORT THE CONCEPT OF 'BEING THERE' AT END OF LIFE}

Jenny Butler. Oakhaven Hospice, Lymington, UK

\subsection{6/bmjspcare-2019-HUKNC.253}

Background 'Being with' dying people is an integral part of nursing (Tornoe, Danbolt, Kvigne, Sorlie, 2014), with hospices best placed to holistically achieve this (Gomes \& Higginson, 2008). However, an increasing demand of patients with complex end of life care and support needs, without requisite increase in funding, means the future challenges facing hospices are considerable (Commission into the Future of Hospice Care, 2012). The value of volunteers supporting people at end of life has now been widely recognised as a response to these challenges (Commission into the Future of Hospice Care, 2012; Radbruch \& Payne, 2009). As hospice nurses identify less availability to sit with dying patients and their families, support was sought from a successfully established volunteer-led bedside companion scheme.

Aim To deliver innovative experience-led training to hospice volunteers: giving them confidence to visit and support patients in the hospice inpatient unit, particularly at end of life. Service will be closely monitored and evaluated to inspire future expansion.

\section{Methods}

- May 2018: met with Volunteer Communications Tutor for initial consultation and model planning;

- June 2018: Scoping for volunteers;

- July 2018: Focus group with hospice multidisciplinary staff;

- Aug-Oct 2018: Final volunteer recruitment;

- Sept 2018: Staff awareness sessions;

- Nov 2018: volunteer training delivered by Volunteer Communications Tutor. Volunteers visit local established bedside companion scheme to 'shadow';

- Jan 2019: Service begins, comprising of mostly rostered scheduled sessions with a written summary recorded and reviewed by ward Sister. Six-weekly debriefing/supportive sessions between volunteers and staff are on-going.

Results

- 8 volunteers recruited. Pilot from January - end April 2019;

- 81 shifts;

- 257 visits;

- 41 patients;

- Taking 114 hours;

- Positive qualitative data collected from volunteers, inpatient staff and patients.

Conclusion Oakhaven's response to the challenges of a changing health and social care landscape by empowering volunteers with the skills to 'be with' hospice patients, as suggested by literature, has shown to be supportive to inpatient staff and 